\title{
Superoxide Scavengers Do Not Prevent Ischemia- Induced Alteration of Cerebral Vasodilation in Piglets
}

\author{
CHARLES W. LEFFLER, CAROLYN C. THOMPSON, WILLIAM M. ARMSTEAD, ROBERT MIRRO,' \\ MASAAKI SHIBATA, AND DAVID W. BUSIJA ${ }^{2}$
}

Laboratory for Research in Neonatal Physiology, Departments of Physiology/Biophysics, Pediatrics, and Obstetrics/Gynecology, University of Tennessee, Memphis, Memphis, Tennessee 38163

\begin{abstract}
Piglet brains generate superoxide during postischemic reperfusion, and topical application of activated oxygen species alters pial arteriolar responses. We investigated effects of pretreatment with scavengers of superoxide and $\mathrm{H}_{2} \mathrm{O}_{2}$ on ischemia-induced alterations of pial arteriolar responses in anesthetized newborn pigs. Four groups were studied: 1) time control, 2) untreated ischemia, 3 ) ischemia pretreated topically and systemically (conjugated to polyethylene glycol) with superoxide dismutase (SOD) and catalase, and 4) ischemia pretreated with Tiron. Pretreatment with SOD conjugated to polyethylene glycol alone during postischemic reperfusion effectively removed superoxide from its site of generation during postischemic reperfusion, but topical SOD was used also as insurance. Piglets were studied before and after $\mathbf{2 0} \mathrm{min}$ of total cerebral ischemia caused by maintaining intracranial pressure above mean arterial pressure. As reported previously, before ischemia, hypercapnia and isoproterenol dilated pial arteries and arterioles and hypercapnia but not isoproterenol increased cortical periarachnoid cerebrospinal fluid 6-keto-prostaglandin $\mathrm{F}_{1 \alpha}$, measured as an index of cerebral cortical prostacyclin synthesis. After cerebral ischemia, pial arterioles did not dilate in response to hypercapnia and 6-keto-prostaglandin $F_{1 \alpha \alpha}$ did not increase, but dilation to isoproterenol was unchanged. The present study found that treatment with SOD/catalase or Tiron did not prevent loss of vasodilation to hypercapnia or the loss of hypercapnia-induced cerebral 6-keto-prostaglandin $\mathbf{F}_{1 \alpha}$ synthesis after cerebral ischemia. The postischemic loss of cerebral vasodilation to hypercapnia does not appear to involve superoxide or a subsequent reduced form of oxygen. (Pediatr Res 33: 164-170, 1993)
\end{abstract}

\section{Abbreviations}

SOD, superoxide dismutase

CAT, catalase

CSF, cerebral spinal fluid

aCSF, artificial cerebral spinal fluid

PEG, polyethylene glycol

NBT, nitroblue tetrazolium

Received May 19, 1992; accepted October 8, 1992

Correspondence: Dr. C. W. Leffler, University of Tennessee. Memphis, 894 Union Avenue (NA 427), Memphis, TN 38163.

R. Mirro was supported by a Clinical Investigatorship from the National Institutes of Health. C. C. Thompson was supported by a Medical Student Fellowship Grant from the National Institutes of Health. Supported by the National Institutes of Health.

'Deceased.

${ }^{2}$ Present address: Department of Physiology/Pharmacology, Bowman Gray School of Medicine, Wake Forest University. Winston-Salem, NC 27103
LT, leukotriene

PG, prostaglandin

Cerebral ischemia in newborn pigs is followed by loss of cerebral vascular responses to hypercapnia and hypotension. The cerebral vasodilation caused by hypercapnia $(1,2)$ and hypotension (3) requires active prostanoid synthesis, whereas dilation to isoproterenol does not (4). After cerebral ischemia, elevated cerebral prostanoid synthesis during hypercapnia and hypotension does not occur (5-7). Vasodilation in response to these stimuli is likewise absent, and the responses to isoproterenol are unchanged.

Superoxide anion and its progressive reduction products, hydrogen peroxide and hydroxyl radical, generated during reperfusion after ischemia, could cause alterations of cerebral microvascular reactivity. Superoxide is produced by the brain during reperfusion after cerebral ischemia in newborn pigs (8). Generation of activated oxygen species on the brain surface by topical application of xanthine oxidase, hypoxanthine, and iron results in changes in microvascular reactivity qualitatively similar to those caused by ischemia/reperfusion: attenuation of pial arteriolar dilation in response to hypercapnia and hypotension without changing responses to topically applied isoproterenol and norepinephrine (9). In other vascular beds, SOD pretreatment has been shown to attenuate vascular damage during postischemic reperfusion (10-12).

The present study was designed to test the hypothesis that superoxide anion and/or subsequent radicals contribute to the loss of vasodilation to hypercapnia and hypotension after cerebral ischemia in newborn pigs.

\section{MATERIALS AND METHODS}

Newborn pigs ( $1-3$ days old) were anesthetized with ketamine hydrochloride ( $33 \mathrm{mg} / \mathrm{kg}$, intramuscularly) and acepromazine (3.3 $\mathrm{mg} / \mathrm{kg}$, intramuscularly) and maintained on $\alpha$-chloralose $\left(50 \mathrm{mg} / \mathrm{kg}\right.$, i.v., initially, plus $\left.5 \mathrm{mg} \cdot \mathrm{kg}^{-1} \cdot \mathrm{h}^{-1}\right)$. The animals were intubated and ventilated with air. Catheters were inserted in the femoral vein for maintenance of anesthesia and blood withdrawal and in the femoral artery to record blood pressure and draw samples for blood gas and $\mathrm{pH}$ analysis. Body temperature was maintained between 37 and $38^{\circ} \mathrm{C}$. The scalp was retracted, and a hole $2 \mathrm{~cm}$ in diameter was made in the skull over the parietal cortex. The dura was cut without touching the brain, and all cut edges were retracted over the bone so that the periarachnoid space was not exposed to damaged bone or damaged membranes. A stainless steel and glass cranial window was placed in the hole and cemented into place with dental acrylic. The space under 
the window was filled with aCSF $\left[150 \mathrm{mM} \mathrm{Na}^{+}, 3 \mathrm{mM} \mathrm{K}^{+}, 2.5\right.$ $\mathrm{mM} \mathrm{Ca}^{2+}, 1.2 \mathrm{mM} \mathrm{Mg}^{2+}, 132 \mathrm{mM} \mathrm{Cl}^{-}, 3.7 \mathrm{mM}$ glucose, $6 \mathrm{mM}$ urea, $25 \mathrm{mM} \mathrm{HCO}-; \mathrm{pH} 7.33 ; \mathrm{PCO}_{2} 6.1 \mathrm{kPa}(46 \mathrm{~mm} \mathrm{Hg}) ; \mathrm{PO}_{2}$ $5.7 \mathrm{kPa}(43 \mathrm{~mm} \mathrm{Hg})]$ through needles incorporated into the sides of the window. The volume of fluid directly beneath the window was $500 \mu \mathrm{L}$ and was contiguous with the periarachnoid space.

Pial arteries 100 to $200 \mu \mathrm{m}$ in diameter and pial arterioles 40 to $80 \mu \mathrm{m}$ in diameter were observed with a dissecting microscope. Diameters were measured with a video micrometer coupled to a television camera mounted on the microscope and a video monitor.

Cerebral cortical periarachnoid CSF $(300 \mu \mathrm{L})$ was collected by placing a syringe on an injection port of the cranial window. CSF was collected by slowly infusing aCSF into one side of the window and allowing the CSF under the window to drip freely into a collection tube on the opposite side.

Cerebral ischemia was produced for $20 \mathrm{~min}$ as described in detail previously $(5-7,13)$. Briefly, during surgery for implantation of the cranial window, a hollow bolt was implanted over the contralateral cerebral cortex. The bolt was connected to a bottle of aCSF. By maintaining a pressure $2 \mathrm{kPa}(15 \mathrm{~mm} \mathrm{Hg})$ greater than mean arterial pressure inside the skull, blood flow throughout the brain and spinal cord was reduced to zero. To prevent inordinate rises in arterial pressure from the Cushing response during cerebral ischemia, blood was withdrawn as necessary and anticoagulated with citrate for reinfusion. After $20 \mathrm{~min}$ of cerebral ischemia, $45 \mathrm{~min}$ of reperfusion were allowed before continuation of experiments. Measurements were made over the next $10 \mathrm{~min}$ to be sure the diameters were stable. Typically, pial arteriolar diameters have stabilized by $45 \mathrm{~min}$ postischemia, with the dilation of reactive hyperemia being short in duration and occurring within the first $10 \mathrm{~min}$ of reperfusion (7).

After flushing the window with aCSF, control measurements of pial arteriolar diameter, arterial blood pressure, blood gases, and $\mathrm{pH}$ were taken. At the end of the 10 -min control period, the CSF from under the window was collected for 6-keto-PGF ${ }_{1 \alpha}$ analysis, an index of cerebral prostacyclin synthesis. Hypercapnia was produced by ventilating with a $10 \% \mathrm{CO}_{2}, 21 \% \mathrm{O}_{2}$, and $69 \%$ $\mathrm{N}_{2}$ mixture. Pial arteriolar diameter and arterial pressure were measured. After 10 min of hypercapnia, the CSF from under the cranial window was collected for 6-keto- $\mathrm{PGF}_{1 \alpha}$ analysis, and an arterial blood sample for blood gases and $\mathrm{pH}$ analysis was drawn. The ventilation mixture was returned to air, and the window was flushed with aCSF four times at 5-min intervals. Another 10min control collection for 6-keto-PGF $\mathrm{i}_{\alpha}$ analysis was taken, and isoproterenol $(1 \mu \mathrm{M})$ was placed under the cranial window. The maximum response within 10 min was recorded. The CSF under the window was collected for $6-$ keto-PGF $F_{\alpha \alpha}$ analysis after $10 \mathrm{~min}$ of exposure. The experiments were continued 65 min later in control animals or after $20 \mathrm{~min}$ of cerebral ischemia followed by approximately $45 \mathrm{~min}$ of reperfusion in the ischemic animals. At this time, responses to hypercapnia and isoproterenol as described above were reexamined. In about $20 \%$ of the animals, the response to isoproterenol was determined before the response to hypercapnia. There was no evidence that the treatment order affected the results, so the results were combined. Vasodilation in response to hypotension was determined by phlebotomy to maintain a mean arterial pressure of one half the control pressure. Pial arteriolar diameter was measured throughout the 10-min period of hypotension and the maximum diameter achieved between 5 and $10 \mathrm{~min}$ of hypotension used for calculation of the response. Hypotension was only examined at the end of the protocol because repeated hypotension modifies the physiologic condition of the piglet.

Piglets were divided into four groups designated as time control, untreated ischemia, SOD/CAT ischemia, and Tiron ischemia.

Time control. Time-control piglets were prepared as described above, and the hollow bolt was implanted in each. After the initial studies of responses to hypercapnia and isoproterenol, 65 min were allowed without treatment; experiments then continued with reexamination of responses to hypercapnia, isoproterenol, and hypotension.

Untreated ischemia. This group received $20 \mathrm{~min}$ of cerebral ischemia after an examination of effects of hypercapnia and isoproterenol. After $45 \mathrm{~min}$ of reperfusion, experimentation was continued by reexamining responses to hypercapnia and isoproterenol. Responses to hypotension were not examined because previous experiments demonstrated loss of dilation to hypotension after ischemia (3).

$S O D / C A T$ ischemia. In this group, treatment to remove superoxide anion under the cranial window was applied topically and systemically to approach the vessel bilaterally. Thirty min before beginning experiments, piglets were given SOD conjugated to PEG (1000 U/kg, i.v.) and CAT conjugated to PEG (10 $000 \mathrm{U} / \mathrm{kg}$, i.v). In addition, the aCSF used under the cranial window and in the ischemia bottle contained SOD $(60 \mathrm{U} / \mathrm{mL})$ and catalase $(1200 \mathrm{U} / \mathrm{mL})$. SOD/CAT ischemia piglets were treated the same as the untreated ischemia piglets. Additionally, the response to hypotension was examined as the last intervention.

To examine the effectiveness of systemically administered PEG-SOD $(1000 \mathrm{U} / \mathrm{kg})$ in dismutating superoxide anion generated by the brain, we measured SOD-inhibitable NBT reduction in four piglets with dual cranial windows implanted using methods described previously $(8,14-16)$. SOD-inhibitable NBT reduction was determined during the first $20 \mathrm{~min}$ of reperfusion after $20 \mathrm{~min}$ of cerebral ischemia in piglets treated systemically with only PEG-SOD (i.e. none was placed in aCSF, in contrast to the SOD/CAT ischemia treatment group).

Tiron ischemia. Because the high molecular weight of SOD might reduce access to superoxide anion within the cell, the smaller molecular weight scavenger of superoxide anion Tiron (4,5-dihydroxy-13-benzene disulfonic acid) (17) (Sigma Chemical Co., St. Louis, MO) was also used. Tiron was administered at $1 \mathrm{~g} / \mathrm{kg}+50 \mathrm{mg} / \mathrm{kg} \cdot \mathrm{min}$ i.v. dissolved in saline with the $\mathrm{pH}$ adjusted to 7.3 with $\mathrm{NaOH}$. Simultaneously, Tiron was administered directly to the pial arterioles in the aCSF $(100 \mathrm{mM}, \mathrm{pH}$ adjusted to 7.3 with $\mathrm{NaOH}$ ). Tiron treatment was begun 30 min before beginning experimentation and continued throughout the experiment. Otherwise, experimentation was as described above for untreated ischemia.

6-keto-PGF $F_{1 \alpha}$ in cortical periarachnoid CSF was analyzed by RIA against an aCSF matrix as described previously (18). All unknowns were processed at three dilutions, with parallelism between the unknown dilution curve and the standard curve required before the result was used. Sample dilutions allowed analysis of prostanoid concentrations between 100 and 50000 $\mathrm{pg} / \mathrm{mL}$. Previously, using this assay, we demonstrated large proportional increases in prostanoids after topical application of arachidonic acid and greater than $90 \%$ decreases in concentrations of all prostanoids examined in cortical periarachnoid fluid after treatment with indomethacin $(10 \mathrm{mg} / \mathrm{kg}, \mathrm{i} . \mathrm{v})$ under basal conditions and when stimulated with exogenous arachidonic acid (19). Our antibodies cross-react minimally (less than 1\%) with other prostanoids studied. Furthermore, target ligands are not displaced from the antibodies by arachidonic acid $(20 \mu \mathrm{g} / \mathrm{mL})$; 5-hydroxyeicosatetraenoic acid or 15-hydroxyeicosatetraenoic acid $(1 \mu \mathrm{g} / \mathrm{mL}) ; \mathrm{LTB}_{4}, \mathrm{LTC}_{4}, \mathrm{LTD}_{4}$, or $\mathrm{LTE}_{4}(5 \mu \mathrm{g} / \mathrm{mL})$; or lipoxin $A_{4}$ or lipoxin $B_{4}(10 \mathrm{ng} / \mathrm{mL})$.

Statistical analysis of the major data sets used repeated measures analysis of variance for four groups over time with contrasts by $t$ tests for preplanned comparisons. $p<0.05$ was required for inference that populations were different.

\section{RESULTS}

The arterial blood pressures, gases, and $\mathrm{pH}$ of the newborn pigs in the four groups before and after ischemia are shown in Table 1. Initial values for all these parameters were comparable 
Table 1. Arterial blood pressures, gases, and $p H$ of newborn pigs*

\begin{tabular}{|c|c|c|c|c|c|c|c|c|c|c|}
\hline & \multicolumn{4}{|c|}{ Before ischemia } & \multicolumn{6}{|c|}{ After ischemia } \\
\hline & Control & $\mathrm{CO}_{2}$ & Control & Isuprel & Control & $\mathrm{CO}_{2}$ & Control & Isuprel & Control & Hypotension \\
\hline \multicolumn{11}{|c|}{$\begin{array}{l}\text { Time control }(n=8 \\
\text { no ischemia) }\end{array}$} \\
\hline $\mathrm{pH}$ & $7.50 \pm 0.02$ & $7.23 \pm 0.02 \dagger$ & & & $7.50 \pm 0.02$ & $27.20 \pm 0.03 \dagger$ & & & & \\
\hline $\mathrm{PO}_{2}(\mathrm{kPa})$ & $10.9 \pm 0.8$ & $10.0 \pm 0.7$ & & & $10.5 \pm 0.7$ & $9.5 \pm 0.9$ & & & & \\
\hline $\mathrm{P} \mathrm{CO}_{2}(\mathrm{kPa})$ & $4.5 \pm 0.3$ & $\begin{array}{c}9.1 \pm 0.5 \dagger \\
(68 \mathrm{~mm} \mathrm{Hg})\end{array}$ & & & $4.7 \pm 0.3$ & $9.1 \pm 0.5 \dagger$ & & & & \\
\hline \multicolumn{11}{|c|}{$\begin{array}{l}\text { Untreated ischemia } \\
\qquad(n=7)\end{array}$} \\
\hline $\mathrm{pH}$ & $7.49 \pm 0.04$ & $+7.25 \pm 0.06+$ & & & $7.41 \pm 0.06$ & $7.16 \pm 0.05 t$ & & & & \\
\hline $\mathrm{PO}_{2}(\mathrm{kPa})$ & $12.3 \pm 0.4$ & $11.7 \pm 0.7$ & & & $10.9 \pm 0.9$ & $10.8 \pm 1.1$ & & & & \\
\hline $\mathrm{P}\left(\mathrm{OO}_{2}(\mathrm{kPa})\right.$ & $4.5 \pm 0.3$ & $\begin{array}{c}8.5 \pm 0.3 \dagger \\
(64 \mathrm{~mm} \mathrm{Hg})\end{array}$ & & & $4.7 \pm 0.3$ & $\begin{array}{c}8.7 \pm 0.4 \dagger \\
(65 \mathrm{~mm} \mathrm{Hg})\end{array}$ & & & & \\
\hline $\mathrm{pH}$ & $7.44 \pm 0.02$ & $2.19 \pm 0.02 \dagger$ & & & $7.39 \pm 0.04$ & $7.16 \pm 0.02 \dagger$ & & & & \\
\hline $\mathrm{PO}_{2}(\mathrm{kPa})$ & $11.3 \pm 0.7$ & $11.2 \pm 0.4$ & & & $10.5 \pm 0.7$ & $10.3 \pm 0.9$ & & & & \\
\hline $\mathrm{P}\left(\mathrm{O}_{2}(\mathrm{kPa})\right.$ & $4.9 \pm 0.1$ & $\begin{array}{c}9.5 \pm 0.4 \dagger \\
(71 \mathrm{~mm} \mathrm{Hg})\end{array}$ & & & $4.9 \pm 0.3$ & $\begin{array}{c}8.8 \pm 0.5 \dagger \\
(66 \mathrm{~mm} \mathrm{Hg})\end{array}$ & & & & \\
\hline $\mathrm{MABP}(\mathrm{kPa})$ & $10.4 \pm 0.5$ & $11.3 \pm 0.4$ & $10.5 \pm 0.5$ & $10.7 \pm 0.5$ & $9.3 \pm 0.4$ & $9.5 \pm 0.5$ & $9.7 \pm 0.8$ & $10.4 \pm 0.8$ & $10.1 \pm 0.7$ & $\begin{array}{c}5.5 \pm 0.1 \dagger \\
(41 \mathrm{~mm} \mathrm{Hg})\end{array}$ \\
\hline \multicolumn{11}{|l|}{$\begin{array}{l}\text { Tiron ischemia } \\
\qquad(n=8)\end{array}$} \\
\hline $\mathrm{pH}$ & $7.48 \pm 0.04$ & $+7.16 \pm 0.03 \dagger$ & & & $7.43 \pm 0.06$ & $7.09 \pm 0.06 \dagger$ & & & & \\
\hline $\mathrm{PO}_{2}(\mathrm{kPa})$ & $10.9 \pm 0.7$ & $11.3 \pm 0.7$ & & & $10.8 \pm 1.1$ & $9.7 \pm 0.8$ & & & & \\
\hline $\mathrm{PCO}_{2}(\mathrm{kPa})$ & $4.3 \pm 0.3$ & $\begin{array}{c}8.9 \pm 0.4 \dagger \\
(67 \mathrm{~mm} \mathrm{Hg})\end{array}$ & & & $3.9 \pm 0.1$ & $\begin{array}{c}8.7 \pm 0.5 \dagger \\
(65 \mathrm{~mm} \mathrm{Hg})\end{array}$ & & & & \\
\hline
\end{tabular}

* Values are mean \pm SEM. Isuprel, isoproterenol (Sigma Chemical Co.); MABP, mean arterial blood pressure.

$\dagger p<0.05$ compared with previous control.

among groups. Furthermore, cerebral ischemia had no significant effect on arterial blood pressures, gases, or $\mathrm{pH}$ in any of the groups of piglets.

Pretreatment of piglets with PEG-SOD completely blocked the increase in SOD-inhibitable NBT reduction during postischemic reperfusion. None of the four piglets pretreated with PEG-SOD had detectable SOD-inhibitable NBT reduction during reperfusion after cerebral ischemia. The minimum detectable is about $1 \mathrm{pmol} \cdot \mathrm{mm}^{-2} \cdot 20 \mathrm{~min}^{-1}$. The undetectable SOD-inhibitable NBT reduction in PEG-SOD-treated piglets after ischemia is in contrast to $8.7 \pm 1.5 \mathrm{pmol} \cdot \mathrm{mm}^{-2} \cdot 20 \mathrm{~min}^{-1}$ in untreated piglets (8). Nevertheless, to ensure high SOD activity around vessels under observation. SOD was also placed in the aCSF of the SOD/CAT group as described in the Materials and Methods.

Hypercapnia caused similar vasodilation of both pial arterioles (Table 2, Fig. 1) and pial arteries (Table 3. Fig. 2) before cerebral ischemia in all four groups of piglets. There were no differences among responses of pial arterioles (Table 2, Fig. 1) or arteries (Table 3, Fig. 2) to topically applied isoproterenol before ischemia either. In the time-control piglets, responses of pial arterioles and pial arteries to hypercapnia and isoproterenol were unchanged after the $65-\mathrm{min}$ interim period between the first trial and the second (Tables 2 and 3, Figs. 1 and 2). In contrast, after cerebral ischemia, neither pial arterioles nor pial arteries dilated in response to hypercapnia, but responses to topical isoproterenol were not changed significantly (Tables 2 and 3, and Figs. 1 and 2). Treatment with PEG-SOD, PEG-CAT, topical SOD, and topical CAT or systemic and topical administration of Tiron did not prevent the loss of the pial vasodilation to hypercapnia after cerebral ischemia (Tables 2 and 3, Figs. 1 and 2). Similar to those of untreated ischemia piglets, pial arterioles of SOD/CAT ischemia and Tiron ischemia piglets dilated in response to isoproterenol after cerebral ischemia.

Hypercapnia (Fig. 3) increased cortical periarachnoid 6-keto-

Table 2. Pial arteriolar responses (mean $\pm \mathrm{SEM}$ ) to hypercapnia $\left(\mathrm{CO}_{2}\right)$ and isoproterenol (Isuprel)

\begin{tabular}{|c|c|c|c|c|c|c|c|c|}
\hline & \multicolumn{8}{|c|}{ Arteriolar diameter $(\mu \mathrm{m})$} \\
\hline & \multicolumn{4}{|c|}{ Before ischemia } & \multicolumn{4}{|c|}{ After ischemia } \\
\hline & Control & $\mathrm{CO}_{2}$ & Control & Isuprel & Control & $\mathrm{CO}_{2}$ & Control & Isuprel \\
\hline Time control $(n=8)$ & $67 \pm 7$ & $96 \pm 9^{*}$ & $70 \pm 7$ & $102 \pm 10^{*}$ & $63 \pm 6$ & $94 \pm 9^{*}$ & $65 \pm 8$ & $92 \pm 10^{*}$ \\
\hline Untreated ischemia $(n=7)$ & $65 \pm 4$ & $91 \pm 4^{*}$ & $66 \pm 4$ & $91 \pm 7^{*}$ & $74 \pm 6$ & $78 \pm 6$ & $69 \pm 8$ & $84 \pm 11^{*}$ \\
\hline SOD/CAT ischemia $(n=10)$ & $62 \pm 4$ & $88 \pm 5^{*}$ & $60 \pm 4$ & $94 \pm 9^{*}$ & $67 \pm 8$ & $67 \pm 11$ & $55 \pm 7$ & $73 \pm 11^{*}$ \\
\hline Tiron ischemia $(n=8) \dagger$ & $79 \pm 10$ & $101 \pm 8^{*}$ & $90 \pm 13$ & $110 \pm 15^{*}$ & $76 \pm 8$ & $75 \pm 9$ & $76 \pm 9$ & $91 \pm 11^{*}$ \\
\hline
\end{tabular}

$* p<0.05$ compared with previous control.

$+n=5$, isoproterenol (Isuprel) 

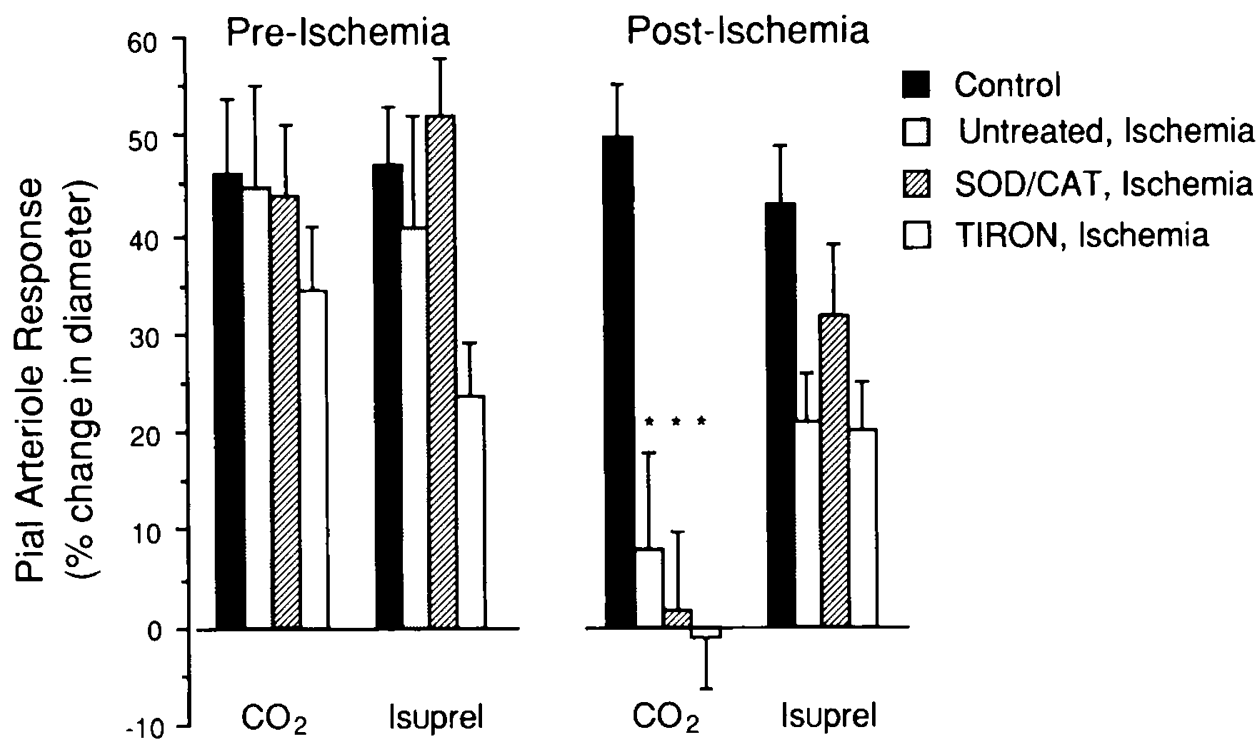

Fig. I. Effects of ischemia on responses of newborn pig pial arterioles to hypercapnia $\left(\mathrm{CO}_{2}\right)$ and isoproterenol $(1 \mu \mathrm{M})(\mathrm{Isuprel}){ }^{*}$. $p<0.05$ compared with preischemia. Number of piglets as in Table 2 (means \pm SEM).

Table 3. Pial arterial responses (mean \pm SEM) to hypercapnia $\left(\mathrm{CO}_{2}\right)$ and isoproterenol (Isuprel)

\begin{tabular}{|c|c|c|c|c|c|c|c|c|}
\hline & \multicolumn{8}{|c|}{ Artery diameter $(\mu \mathrm{m})$} \\
\hline & \multicolumn{4}{|c|}{ Before ischemia } & \multicolumn{4}{|c|}{ After ischemia } \\
\hline & Control & $\mathrm{CO}_{2}$ & Control & Isuprel & Control & $\mathrm{CO}_{2}$ & Control & Isuprel \\
\hline Untreated ischemia $(n=5)$ & $114 \pm 10$ & $157 \pm 14^{*}$ & $125 \pm 8$ & $161 \pm 12^{*}$ & $130 \pm 10$ & $134 \pm 18$ & $117 \pm 16$ & $138 \pm 21$ \\
\hline $\mathrm{SOD} / \mathrm{CAT}$ ischemia $(n=10)$ & $162 \pm 21$ & $207 \pm 23^{*}$ & $167 \pm 23$ & $240 \pm 28^{*}$ & $182 \pm 29$ & $178 \pm 27$ & $147 \pm 25$ & $189 \pm 33^{*}$ \\
\hline Tiron ischemia $(n=7) \dagger$ & $151 \pm 16$ & $175 \pm 13^{*}$ & $168 \pm 15$ & $201 \pm 21^{*}$ & $158 \pm 12$ & $164 \pm 12$ & $159 \pm 8$ & $177 \pm 13$ \\
\hline
\end{tabular}

${ }^{*} p<0.05$ compared with previous control.

$+n=4$. isoproterenol (Isuprel).

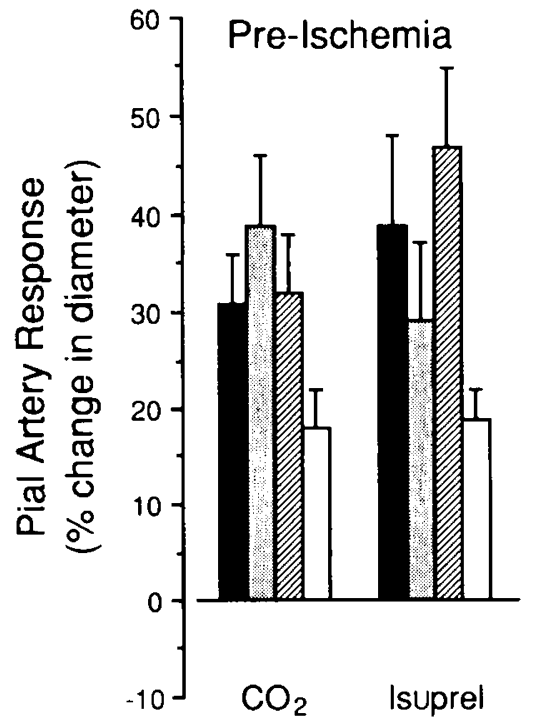

Post-Ischemia

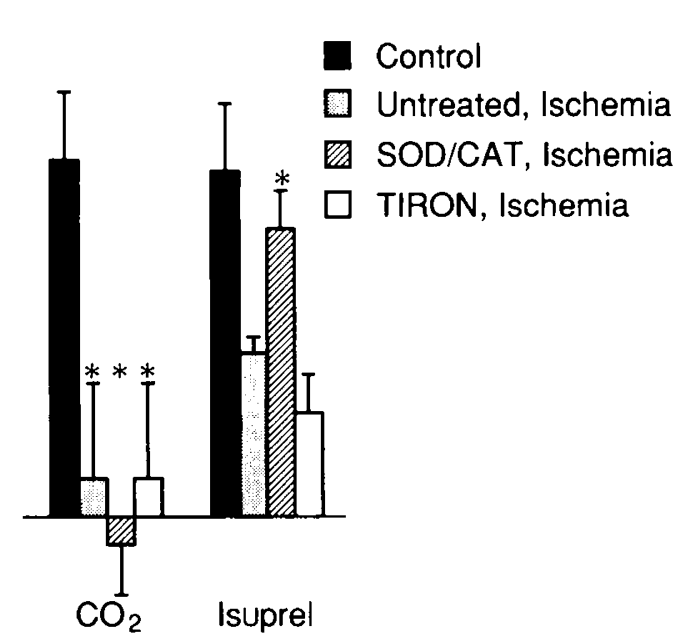

Fig. 2. Effects of ischemia on responses of newborn pig pial arteries to hypercapnia $\left(\mathrm{CO}_{2}\right)$ and isoproterenol $(1 \mu \mathrm{M})(I$ suprel $)$. ${ }^{*}, p<0.05$ compared with preischemia. Number of piglets as in Table 3 (means \pm SEM).

$\mathrm{PGF}_{1,}$ concentration similarly in all four groups of piglets before cerebral ischemia. During the second period of hypercapnia. cortical periarachnoid 6-keto-PGF ${ }_{1 \alpha}$ concentration once again increased in the time-control group. However, after cerebral ischemia. hypercapnia did not increase 6-keto-PGF ${ }_{1 ،}$ in untreated, SOD/CAT-treated, or Tiron-treated piglets (Fig. 3). Isoproterenol did not increase 6-keto-PGF ${ }_{1,}$ before or after ischemia in any group (data not shown).

Similar to results with hypercapnia. SOD/CAT pretreatment did not prevent the total loss of autoregulatory vasodilation of pial arterioles in response to hypotension after cerebral ischemia (Fig. 4).

\section{DISCUSSION}

As reported previously (5-7), cerebral ischemia selectively inhibits specific dilator responses of newborn pig pial arterioles. Superoxide anion or subsequent reduction products do not ap- 


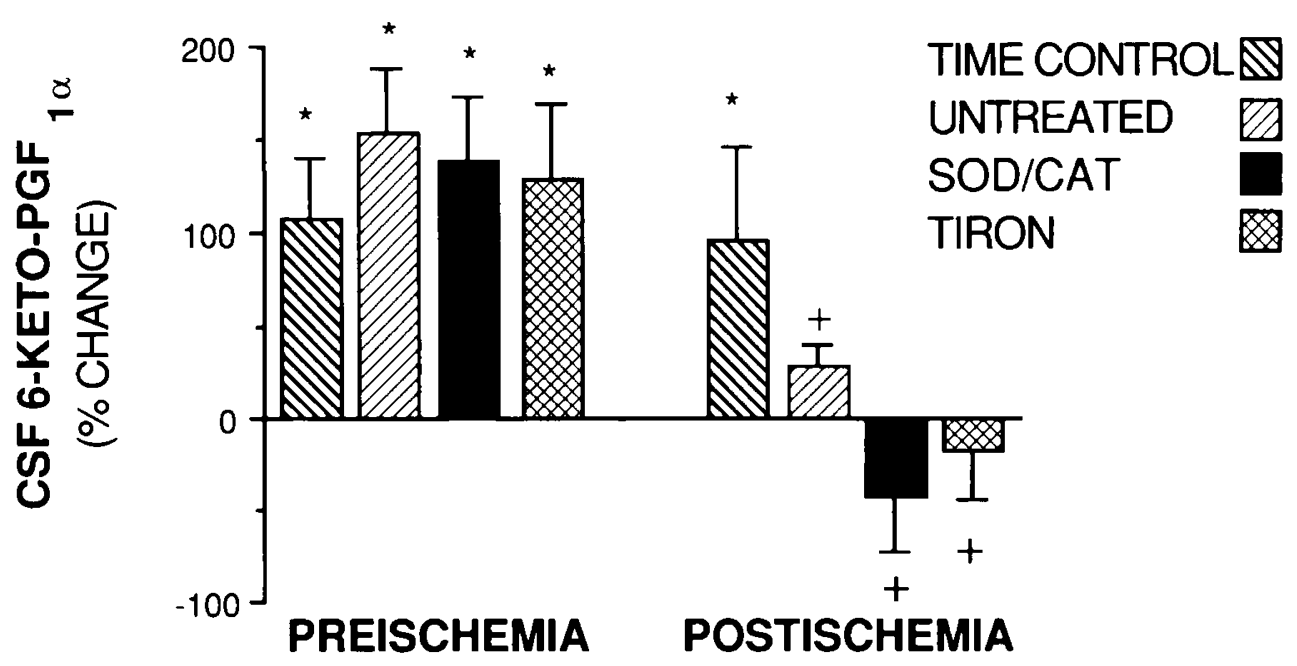

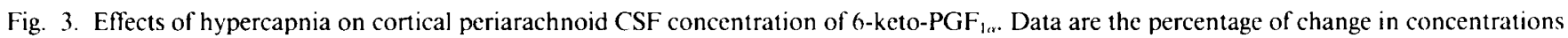
between normocapnia and hypercapnia. ${ }^{*} . p<0.05$ compared with zero change. ${ }^{+} . p<0.05$ compared with preischemia response. $n=7$. time control: $n=5$, untreated; $n=7$, SOD/CAT: $n=6$. Tiron (means \pm SEM).

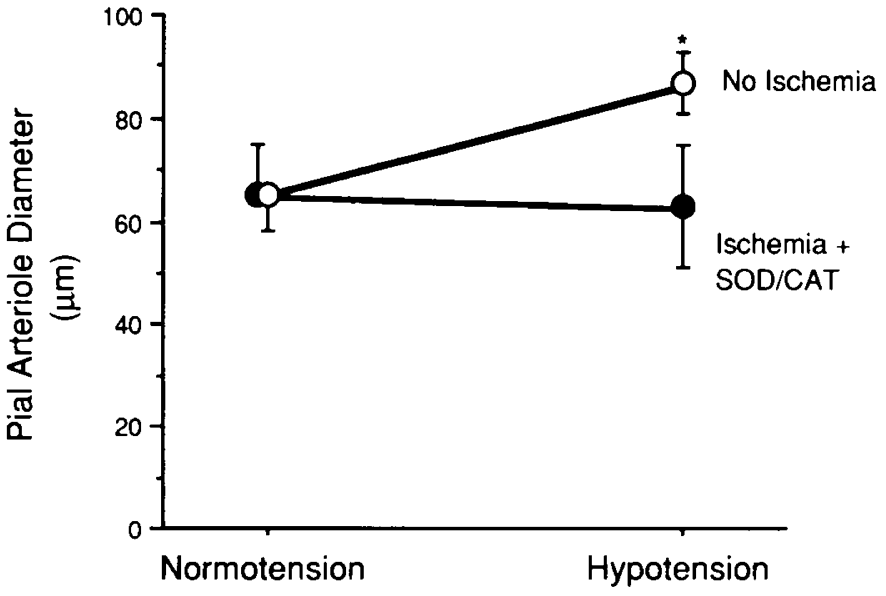

Fig. 4. Effect of hypotension on pial arteriolar diameters of newborn pigs not exposed to cerebral ischemia and those pretreated with SOD/ CAT and exposed to ischemia (means \pm SEM).

pear to be involved in the loss of responses, inasmuch as the present experiments found systemic and topical administration of high concentrations of superoxide anion scavengers prevented neither the loss of pial arteriolar dilation in response to hypercapnia nor the postischemia attenuation of hypercapnia-induced cerebral prostanoid synthesis.

These results are somewhat surprising in light of the fact that superoxide anion production is increased upon reperfusion of ischemic newborn pig brains (8) and superoxide anion generated on the brain surface, albeit at about three times that measured during postischemic reperfusion, can selectively attenuate prostanoid-associated dilation of pial arterioles (9). In other studies, SOD has been found to be protective in some cases but not others. For example, pretreatment with SOD attenuated postischemic coronary microvascular injury assessed by leakage of radiolabeled proteins (10). Pretreatment with SOD also protected perfused rat hearts from postischemic loss of endothelium-dependent vasodilation in response to acetylcholine (11). However, the decrease in prostacyclin production by human umbilical vein endothelial cells in culture that accompanies reoxygenation of anoxic endothelium is only slightly attenuated by treatment with SOD or CAT (20), which is consistent with the present findings.

The conclusions in the present study are based on the assumption that the inhibitors used reduced or eliminated superoxide anion. This assumption is reasonable for both SOD/CAT and Tiron. Using the SOD-inhibitable NBT reduction method to detect superoxide anion production, we found that systemic administration of PEG-SOD effectively inhibited the cerebral accumulation of superoxide anion during reperfusion after ischemia. To ensure total removal of superoxide from around the vessels under observation, we not only used PEG-SOD systemically, but also placed SOD in the aCSF bathing the cerebral arteries and arterioles. Thus, one must conclude that little extracellular superoxide anion could accumulate under these conditions. Superoxide production in relation to PGH synthase activity, which appears to be the primary source of superoxide anion generation during reperfusion of the newborn pig brain, occurs intracellularly, with superoxide anion leaving the cells via anion channels (21). Therefore, one must consider the possibility that the superoxide anion could affect the vascular responses without leaving the cell. The protein SOD does not enter cells well. However, conjugation of SOD to PEG does increase uptake by endothelial cells in culture (22), and SOD has been shown to be highly effective in blocking PGH synthase-dependent responses to exogenous arachidonic acid, bradykinin, and 5,6 epoxyeicosatrienoic acid (23-25). Nevertheless, further assurance that superoxide anion is not involved in the loss of prostanoid-associated responses after ischemia was sought by using an inhibitor reported to be capable of scavenging intracellular superoxide anion. Because we could not measure intracellular superoxide anion, we used maximal concentrations of Tiron. Tiron appears to be effective as a superoxide anion scavenger and appears to enter cells and remove superoxide anion. Although no experiments have demonstrated that Tiron penetrates blood vessels. ability to act intracellularly in lymphocytes and neutrophils suggests that Tiron is not excluded by cell membranes. Devlin $e t$ al. (17) showed that Tiron was capable of inhibiting lymphocytemediated cytolysis, whereas SOD and catalase were not. The requirement for intimate cell contact in lymphocyte-mediated cytolysis prevents the large enzymes from access to the area of activity, whereas the smaller Tiron can cross the cell membrane to remove the superoxide anion even when there is cell-to-cell contact. Melinn and McLaughlin (26) demonstrated that Tiron was highly effective in inhibiting lucigenin-amplified chemiluminescence produced by superoxide anion, whether produced directly using xanthine and xanthine oxidase or by opsonized xymosan-activated neutrophils, and was much more effective than a very high concentration of SOD in the neutrophil preparation, suggesting that Tiron removes the intracellular superoxide anion. These effects were obtained at $10 \mathrm{mM}$. We used a 10 -fold higher concentration of Tiron in the CSF, bathing the vessels under observation, and also infused Tiron at the maximum rate tolerated by the piglet and found this aggressive treatment to be 
completely ineffective in preventing the loss of prostanoid-associated responses after cerebral ischemia. Although a positive result may have been difficult to interpret due to potential and unknown alternative effects of Tiron and the exceedingly high doses used, the total lack of protective effect of this treatment removes this difficulty and allows us to suggest that intracellular superoxide anion generation is not responsible for the loss of prostanoid-associated responses of pial arterioles in newborn pigs after ischemia.

It is not likely that activated oxygen species generated independently of superoxide anion cause the changes observed. The single electron reduction of oxygen to produce superoxide anion introduces oxygen to the free radical cascade with subsequent activated oxygen species being generated by further reduction. Thus, elimination of superoxide by accentuating reduction to $\mathrm{H}_{2} \mathrm{O}_{2}$ and removing the $\mathrm{H}_{2} \mathrm{O}_{2}$ with $\mathrm{CAT}$ eliminates hydroxyl radical as well.

In the present study, pretreatment of newborn pigs ( $1-3 \mathrm{~d}$ old $)$ with $1000 \mathrm{U}$ PEG-SOD $/ \mathrm{kg}$ completely inhibited the increase in SOD-inhibitable NBT reduction that occurs upon reperfusion of ischemic pig brains. On initial examination, these data appear in contrast to those of Haun et al. (27), who found treatment of pigs 1 to $2 \mathrm{wk}$ old with $8000 \mathrm{U} / \mathrm{kg}$ did not increase SOD activity in the brain homogenates. Though possible, we feel it is unlikely that the ages of the piglets could account for these apparent differences. PEG-SOD may not readily cross the blood-brain barrier and enter the brain parenchyma in large quantities in our piglets either. Instead, systemic administration of PEG-SOD could increase cerebral vascular endothelial cell SOD activity without augmenting the SOD activity of brain homogenates, as reported by Haun et al. (27). These data could suggest that cerebral endothelial cells are largely responsible for increased superoxide generation upon postischemic reperfusion. However, this discussion is not directly relevant to the major conclusions of the present study, inasmuch as SOD was also applied topically to bathe the arteries and arterioles under investigation, thereby circumventing the blood-brain barrier.

Because it appears that activated oxygen species are not responsible for the loss of prostanoid-associated vascular responses after ischemia in the newborn pig, the mechanism accounting for this selective alteration of cerebral reactivity remains unknown. Inactivation of PGH synthase, like superoxide anion, does not appear to be involved, because conversion of exogenous arachidonic acid to prostanoids on the brain surface is not altered after cerebral ischemia (28). Therefore, currently available evidence would suggest that ischemia decreases the release of arachidonic acid in response to the specific induction stimuli. Inasmuch as phospholipase $A_{2}$ appears to be involved in the increase in prostanoid synthesis caused by hypercapnia in newborn pigs (2), it is possible that ischemia results in phospholipase $\mathrm{A}_{2}$ inactivation. Another possibility that must be considered is that of depletion of arachidonic acid from a specific membrane pool that provides a source for hypercapnia- and hypotensioninduced arachidonic acid release. The marked increase in free arachidonic acid induced by ischemia $(29,30)$ makes such a possibility more attractive. Consistent with this hypothesis, we recently reported that topically applied arachidonic acid restores pial arteriolar dilation to hypercapnia after ischemia (31).

Total brain ischemia results in neuroendocrinologic changes that could affect subsequent cerebral vascular responsiveness. The present experiments used elevation of intracranial pressure coupled with suppression of hypertension by blood withdrawal to produce ischemia. The rationale for this selection has been discussed previously (13). It does not appear that the acute neuroendocrine changes are causing the change in vascular reactivity because the loss of response to hypercapnia is sustained for at least $24 \mathrm{~h}(6)$. Of course, such changes could contribute to vascular damage during ischemia/reperfusion. The cerebral ischemic response producing the neuroendocrinologic changes would occur regardless of whether ischemia was produced by elevation of intracranial pressure or occlusion of the carotid and vertebral arteries.

In conclusion, although ischemia-reperfusion caused marked elevation of superoxide anion production by the newborn pig brain and activated oxygen species are capable of attenuating cerebral vasodilation in response to hypercapnia and hypotension, the loss of dilator responses to these stimuli after ischemia of the newborn pig brain does not appear to involve superoxide anion or a subsequent reduced form of oxygen.

Acknowledgments. The authors thank M. Jackson, N. Leffler, A. Fedinec, J. Pirani, W. Gannaway, M. Craig, and O. Burkes for their technical assistance. We thank K. Arheart, Department of Biostatistics and Epidemiology, for performing statistical analyses.

The animal protocols were reviewed and approved by the Animal Care and Use Committee of the University of Tennessee, Memphis.

\section{REFERENCES}

1. Leffler CW, Busija DW 1985 Prostanoids in cortical subarachnoid cerebrospinal fluid and pial artery diameter in newborn pigs. Circ Res 57:689-694

2. Wagerle LC, Mishra OP 1988 Mechanisms of $\mathrm{CO}_{2}$ responses in cerebral arteries of the newborn pig: role of phospholipase, cyclooxygenase, and lipoxygenase pathways. Circ Res 62:1019-1026

3. Leffler CW, Busija DW 1987 Prostanoids and pial arteriolar diameter in hypotensive newborn pigs. Am J Physiol 252:H687-H69l

4. Busija DW, Leffler CW 1987 Eicosanoid synthesis elicited by norepinephrine in piglet parietal cortex. Brain Res 403:243-248

5. Leffler CW, Busija DW, Beasley DG, Armstead WM, Mirro R 1989 Postischemic cerebral microvascular responses to norepinephrine and hypotension in newborn pigs. Stroke 20:541-546

6. Leffler CW, Busija DW, Armstead WM, Mirro R, Beasley DG 1989 Ischemia alters cerebral vascular response to hypercapnia and acetylcholine in piglets. Pediatr Res 25:180-183

7. Leffler CW. Beasley DG. Busija DW 1989 Cerebral ischemia alters cerebral microvascular reactivity in newborn pigs. Am J Physiol 257:H266-H271

8. Armstead WM, Mirro R, Busija DW. Leffler CW 1988 Postischemic generation of superoxide anion by newborn pig brain. Am J Physiol 255:H401-H403

9. Leffler CW, Busija DW. Armstead WM, Shanklin DR, Mirro R. Thelin O 1990 Activated oxygen and arachidonate effects on newborn cerebral arterioles. Am J Physiol 259:H1230-H1238

10. Danber IM, Lesnefsky EJ, Van Benthuysen KM, Weil JV, Howartz LD 1991 Reactive oxygen metabolite scavengers decrease functional coronary microvascular injury due to ischemia-reperfusion. Am J Physiol 260:H42-H49

11. Tsao PS. Lefer AM 1990 Time course and metabolism of endothelial dysfunction in isolated ischemic- and hypoxic-perfused rat hearts. Am J Physio 259:H1660-H1666

12. Granger DN, Hollwarth ME, Parks DA 1986 Ischemia reperfusion injury: role of oxygen-derived free radicals. Acta Physiol Scand Suppl 548:47-63

13. Leffler CWS, Busija DW, Mirro R. Armstead W, Beasley DG 1989 Effects of cerebral ischemia on cerebral blood flow and cerebral oxygen consumption of neonatal pigs. Am J Physiol 257:H1917-H1926

14. Armstead WM, Mirro R. Leffler CW, Busija DW 1989 Cerebral superoxide anion generation during seizures in newborn pigs. J Cereb Blood Flow Metab 9:175-179

15. Mirro R, Armstead WM. Busija DW. Leffler CW 1989 Blood-induced superoxide anion generation by newborn pig cerebral cortex. Am J Physiol 257:H1560-H1564

16. Pourcyrous M. Lefner CW. Mirro R. Busija DW 1990 Brain superoxide anion generation during asphyxia and reventilation in newborn pigs. Pediatr Res 28:618-622

17. Devlin RG, Lin CS, Perper RJ. Dougherty H 1981 Evaluation of free radical scavengers in studies of lymphocyte-mediated cytolysis. Immunopharmacology $3: 147-159$

18. Leffler CW, Busija DW 1985 Prostanoids in cortical subarachnoid cerebrospinal fluid and pial artery diameter in newborn pigs. Circ Res 57:689-694

19. Leffler CW, Busija DW 1985 Arachidonate metabolism on the cerebral surface of newborn pigs. Prostaglandins 30:81-88

20. Hempel SL, Haycraft DL. Hoak JC. Spector AA 1990 Reduced prostacyclin formation after reoxygenation of anoxic endothelium. Am $J$ Physiol 259:C738-C745

21. Lynch RE, Fridovich I 1978 Permeation of erythrocyte stroma by superoxide radical. J Biol Chem 253:4697-4699

22. Beckman JS, Minor RL, White CW, Repine JE, Rosen GM. Freeman BA 1988 Superoxide dismutase and catalase conjugated to polyethylene glycol increases endothelial enzyme activity and oxidant resistance. $\mathrm{J}$ Biol Chem 263:6884-6892

23. Kontos HA. Wei EP, Povlislock JT, Christman CW 1984 Oxygen radicals mediate the cerebral arteriolar dilation from arachidonate and bradykinin in cats. Circ Res 55:295-303 
24. Rosenblum WI 1987 Hydroxyl radical mediates the endothelium-dependent relaxation produced by bradykinin in mouse cerebral arterioles. Circ Res 61:601-603

25. Ellis EF, Police RF, Yancey L, Mckinney JS, Amruthesh SC 1990 Dilation of cerebral arterioles by cytochrome P-450 of arachidonic acid. Am J Physiol 259:H $1171-\mathrm{H} 1177$

26. Melinn M, McLaughlin M 1986 Hydroxyl radical scavengers inhibit human lectin-dependent cellular cytotoxicity. Immunology 58:197-202

27. Haun SE, Kirsch JR. Helfaer MA, Kubos KL. Traystman RJ 1991 Polyethylene glycol-conjugated superoxide dismutase fails to augment brain superoxide dismutase activity in piglets. Stroke 22:655-659
28. Leffler CW, Mirro R, Armstead WM, Busija DW, Thelin O 1990 Prostanoid synthesis and vascular responses to exogenous arachidonic acid following cerebral ischemia in piglets. Prostaglandins 40:241-248

29. Wieloch T, Siesjo BK 1982 Ischemic brain injury: the importance of calcium. lipolytic activities, and free fatty acids. Path Biol 30:269-277

30. Abe K. Kogure K, Yamahoto H, Imazawa M, Miyamoto K 1987 Mechanism of arachidonic acid liberation ischemia in gerbil cerebral cortex. J Neurochem 48:503-509

31. Leffler CW, Mirro R, Armstead WM, Shibata M 1992 Topical arachidonic acid restores pial arteriolar dilation to hypercapnia of postischemic newborn pig brain. Am J Physiol 263:H746-H751 